\title{
ICT BASED TELEMEDICINE FOR THE EGYPTIAN SOCIETY
}

\author{
Hafez A. Fouad ${ }^{1}$ and Haythem H. Abdullah ${ }^{2}$ \\ ${ }^{1}$ Microelectronics Department, Electronics research Institute, Giza, Egypt \\ hafez@eri.sci.eg \\ ${ }^{2}$ Microwave Department, Electronics research Institute, Giza, Egypt \\ haythm_eri@yahoo.com
}

\begin{abstract}
The One of the most challenging problems that encounter the Egyptian society is the lack of significant health care in the rural areas. This problem leads to more severe problems that face the society; the patients from the different rural areas needs to travel to the Egyptian capital where the most experienced physicians are available. This will make overhead not only on the patient budget but on the country budget since the focus on the capital makes a severe traffic problem which threaten most of the economic sectors. The telemedicine is considered one of the most important solutions that could mitigate the accumulated problems of lack of experienced physicians in the Egyptian rural areas. The application of the telemedicine encounters several challenges in Egypt; the lack in the experience in dealing with the telemedicine in these areas and the problem of insufficient medical experts that could fulfil the gab. In this paper, a new ICT-based telemedicine system is proposed to serve the Egyptian society. The portal is already released and snapshots are included
\end{abstract}

\section{KEYWORDS}

Telemedicine, ICT, Information communication technology,

\section{INTRODUCTION}

In this work, an implementation of Information and Communication Technology (ICT) based solution could be considered to realize equal access to proper health care to all citizens, despite the limited resources. ICT applied to health care holds the promise of increasing access to health care to where it is underserved. An ICT based system is designed to allow physicians to consult a specialist about a case without sending the patient to the location where the specialist is working. This will increase access of medical care to rural areas as an example.

Telemedicine can be a cost effective solution to fill the gap created by the lack of highly qualified experts in different fields of medicine in rural areas as well as in urban areas in Egypt. Also the system is supported by Arabic language to help most of Egyptian people. It allows medical personnel at the underserved areas to get specialist support from hospitals in big cities. By doing so, application of telemedicine addresses two problems facing the health care system of the country: shortage of health care services and uneven resource distribution. This is particularly important in rural areas that lack the means to get access to proper health care and unable to employ medical personnel. It is also important in the cities as a mean to get access to advanced health care systems and specialist support from physicians living abroad as a case study.

Natarajan Meghanathan et al. (Eds) : ITCSE, ICDIP, ICAIT - 2013

pp. 53-64, 2013. (C) CS \& IT-CSCP 2013

DOI : $10.5121 /$ csit.2013.3906 
Historically, Tele-medicine started when National American Space Agency (NASA) began to study the physiological changes of the astronauts during their space journeys. The scientists proved the possibility of monitoring the physiological functions such as blood pressure, heart beats and body temperature by doctors on the earth [1][2]. The other early experiments revealed that tele-diagnose and transmitting medical data can be done. The modern progresses in the field of data integration, digital images, and transmission through different multi-media have achieved great success. Consequently there is increase in the tele-medicine projects all over the world. The most world-wide applications are in the field of tele-radiology, and tele-conferences. Teleradiology stations are estimated at ten thousand stations. The project transmits images of normal ray films, ultra sound waves and nuclear medicine films without any effect on the quality of the photos. The results of the brain electricity plans, heart electricity and echo can be transmitted clearly [3].

Tele-medicine and E-Health target improving communications between remote health centers and the hospitals in rural areas and cities on one side and international specialists on the other hand. Tele-medicine aims at better pharmaceutical materials and other medical materials. Thus this EHealth project leads to providing these needs. Tele-medicine aims to present medical services in rural areas parallel to those presented in large cities and capitals [4]. Some websites are specialized in transmitting information not only in written form but also publishing consultations directly via sound, Vedios and photos. Some sites transmitted " tele-visual medical conferences " in agreement with universities in Europe and America which allows direct contact Via sound and photo for many people in several different areas where the conference activities are transmitted via communication network to all those who want to participate tele-medicine uses sound and image signals integration technology according to certain media techniques with the medical experience to provide tele-health care services ( tele-diagnose, consultation and remedy ) such as tele-radiology, tele-dermatology, tele-pathology, tele-monitoring and tele-surgery where some operations are carried out via video or robot to facilitate the medical consultations for emergency cases [5][6].

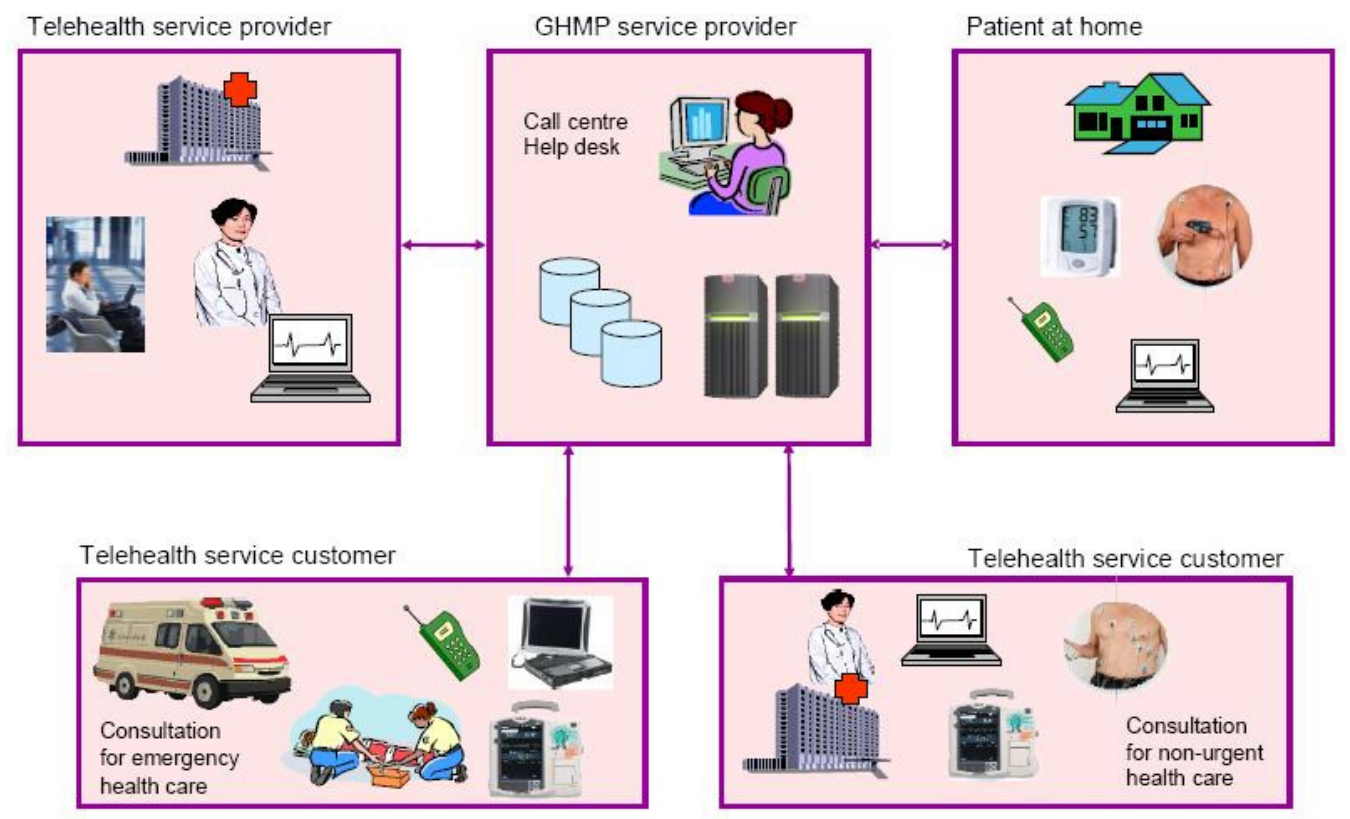

Fig.1. Concept of Telemedicine [5] 


\section{PROBLEM DESCRIPTION AND SUGGESTED SOLUTIONS}

The telemedicine system has two main parts; the patient side and the physician side. Regarding the doctor part, it is worth starting with the registration of the doctor in the system data base. The doctor has two types of registration; a free one and a distinct registration. The distinct registration allows the doctor to add complete information about him as an advertising mean such as his certificates, success stories, his complete contacts and schedule,...etc.. As shown in the flow chart of Figure 2, the administrator at ainmedical manages the process completely in order to ensure a valid data trustiness and then activate the telemedicine feature for the registered doctor up on his request. The second partner in the portal is the patient. In order to enable the patient to store his medical records, get up to date medical news, ask questions, add comments, or book a session with his favorite doctor, he needs only to have a free membership. The administration of the patients' registration on the portal database is outlined in the flow chart of Figure 3.

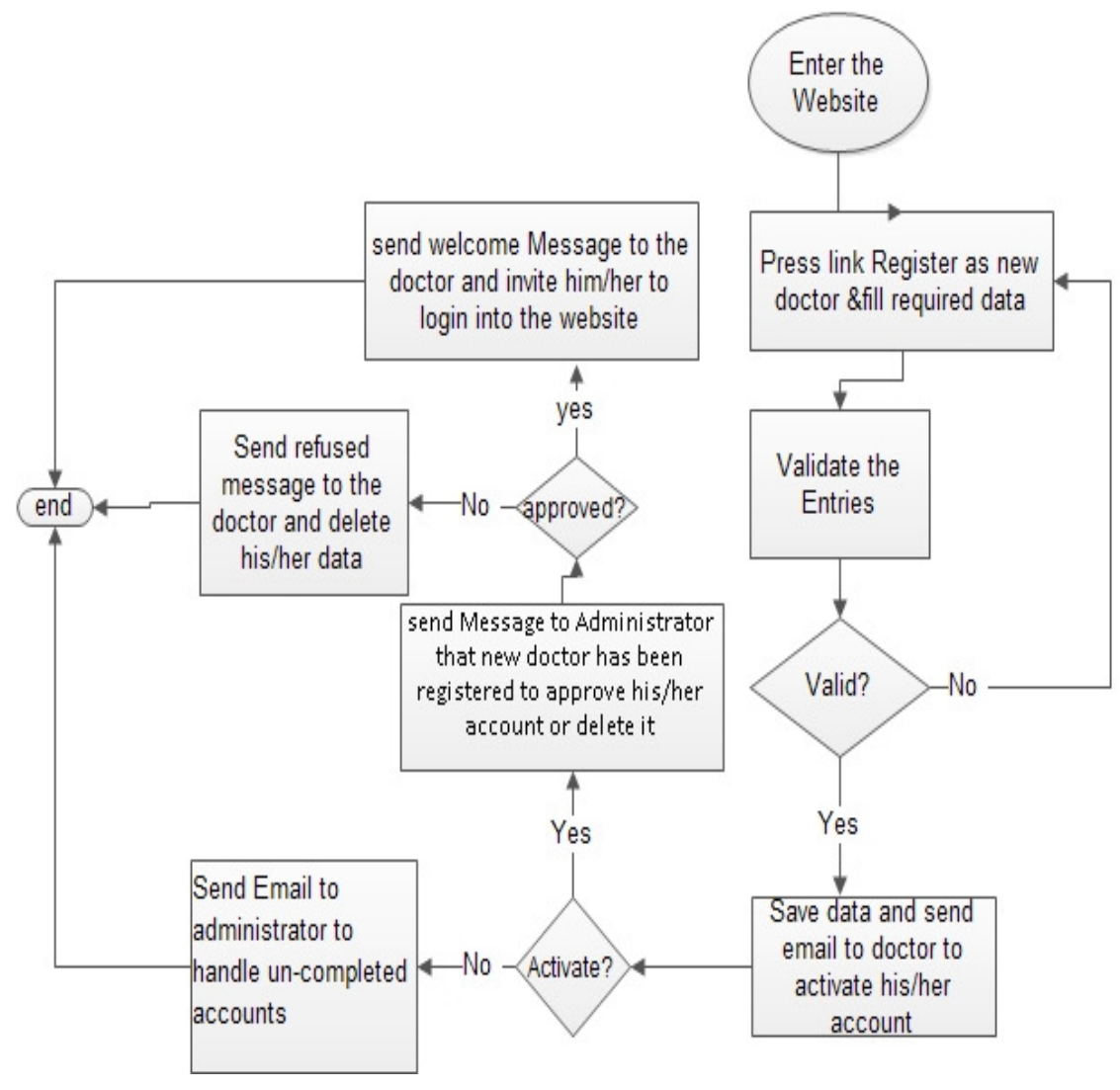

Fig.2. Doctor Registration Flow chart 


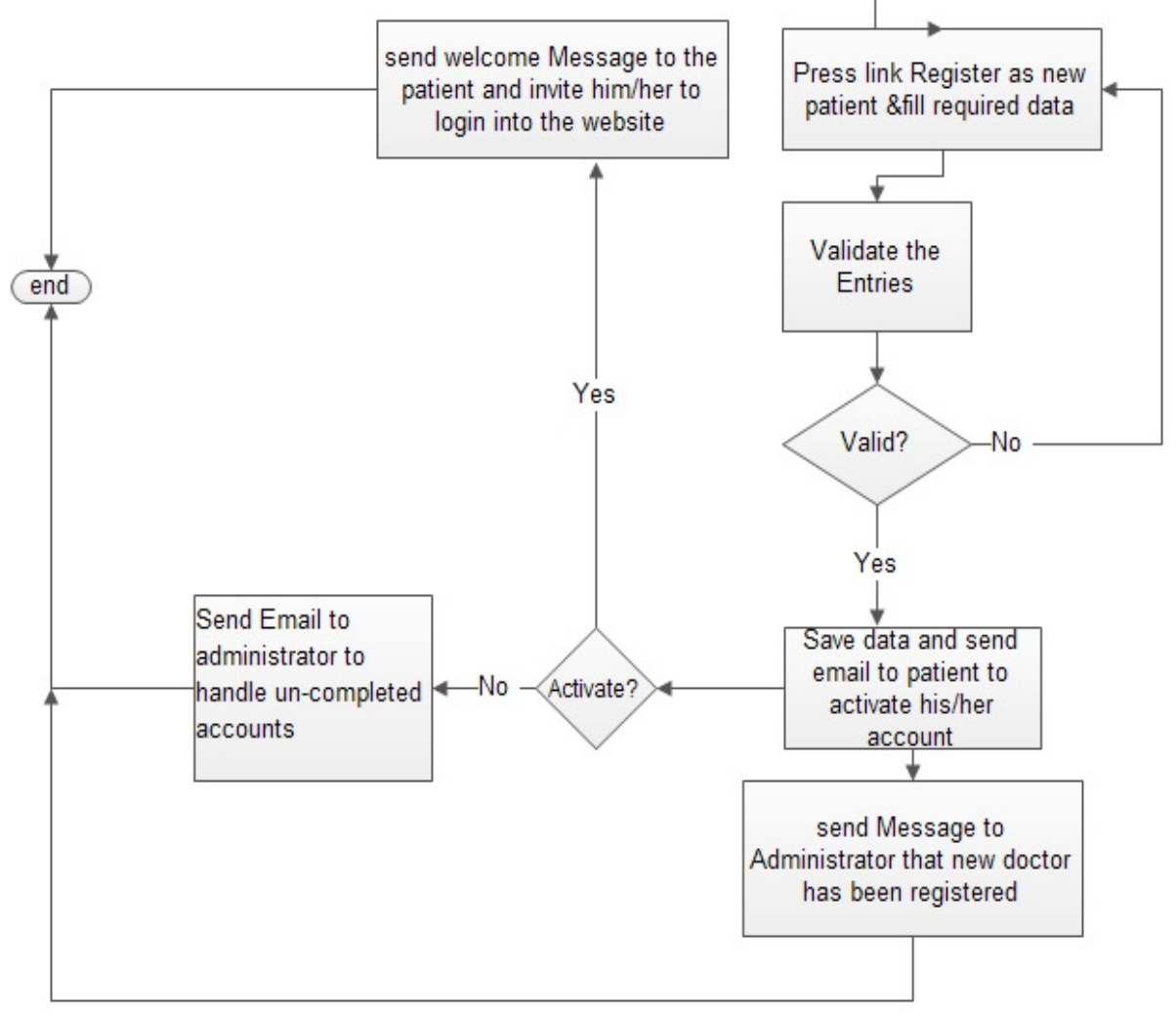

Fig.3. Patient Registration Flow chart

The proposed portal, allows the doctor to set his schedule and fees and edit them regularly if necessary. The doctor is the only person that manages and accepts the booking request from different patients according to the flow chart shown in Figure 4. After the registration of both the patient and the doctor, the scenario between the patient and the doctor during the investigation process starts as follows; the patient is introducing his basic information such as the weight, length, his patient history and the current complain before starting the session. The doctor in his window has the possibility to navigate through the patient medical record then starting the session. There will be a video conference between the doctor and the patient during the doctor pre-assigned session. The doctor can select between the different radiographs or analysis then submit it to the patient window followed by the prescription. The patient can print the required radiographs and analysis with the prescription. Before leaving the session, the doctor can assign another session for the patient for following up if necessary. The doctor will start the second session with another patient directly or he can assign a rest time between sessions. 


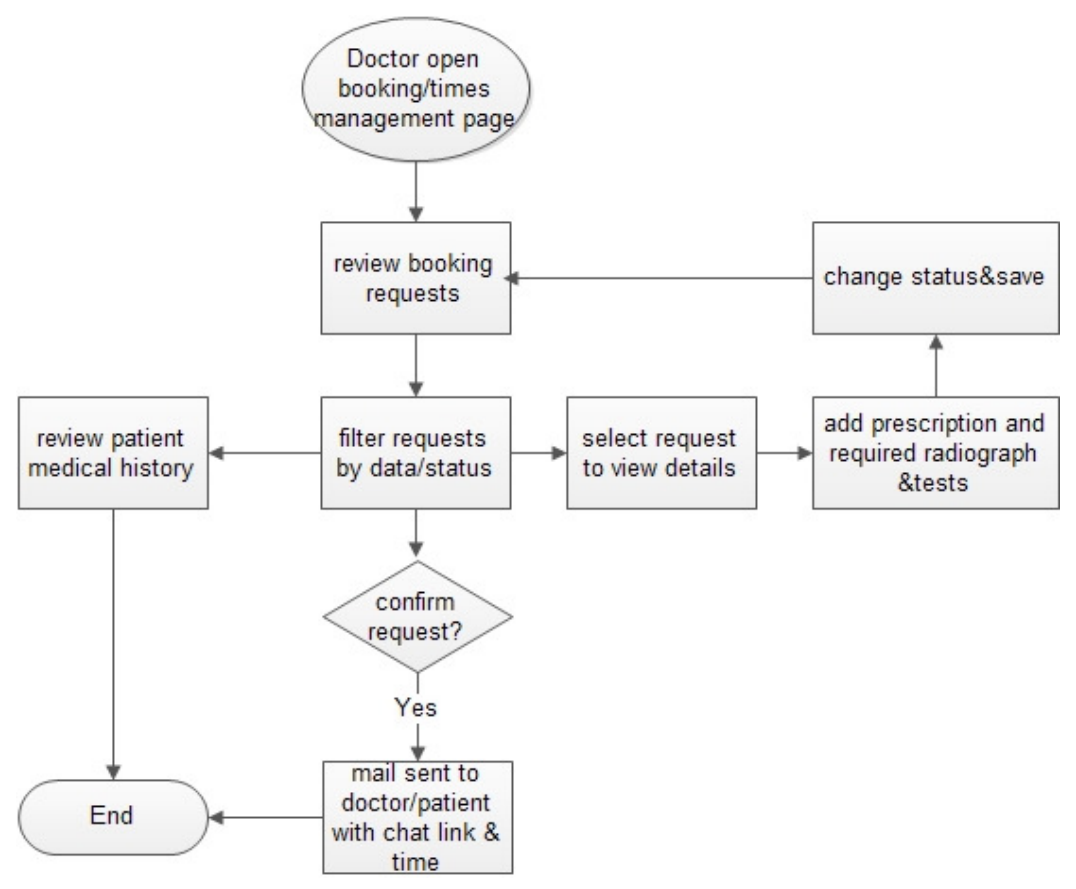

Fig.4. The Management of the Patients' Booking

\section{The Authentication Phase Work for Doctors and Patients}

Doctor Registration, the system Requirements are registration of a new user as Doctor which allows him to a new doctor to become a member of the AinMedical portal as illustrated in Figure 5 .

The system asks the doctor to register as a new user to be a member in Ainmedical portal if it is the first time to visit the portal. In order to be able to register as new member at Ainmedical, the doctor must have an Email address to send him a message for the activation of his account to ensure his belonging data. The message that is sent to the doctor is also send to the Ainmedical admistrator to approve or delete his/her account. If AinMedical's Administrator approved the doctor registration, AinMedical presents welcome page for New Doctor and provide a link to login his account 


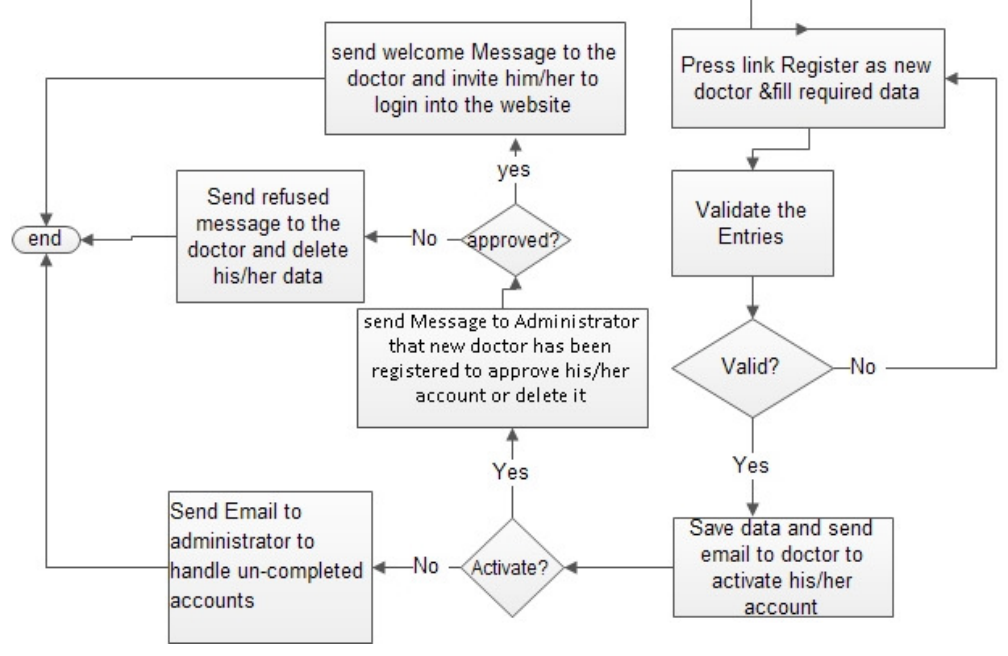

Fig.5. Doctor Registration

Patient Registration, Similar remarks as the doctors are assigned for the patient to be a member of the Ain medical portal except that no administration processes are required. In case a new Patient has been registered, AinMedical presents welcome page for New Patient and provide link to login his/her account as indicated in Figure 6.

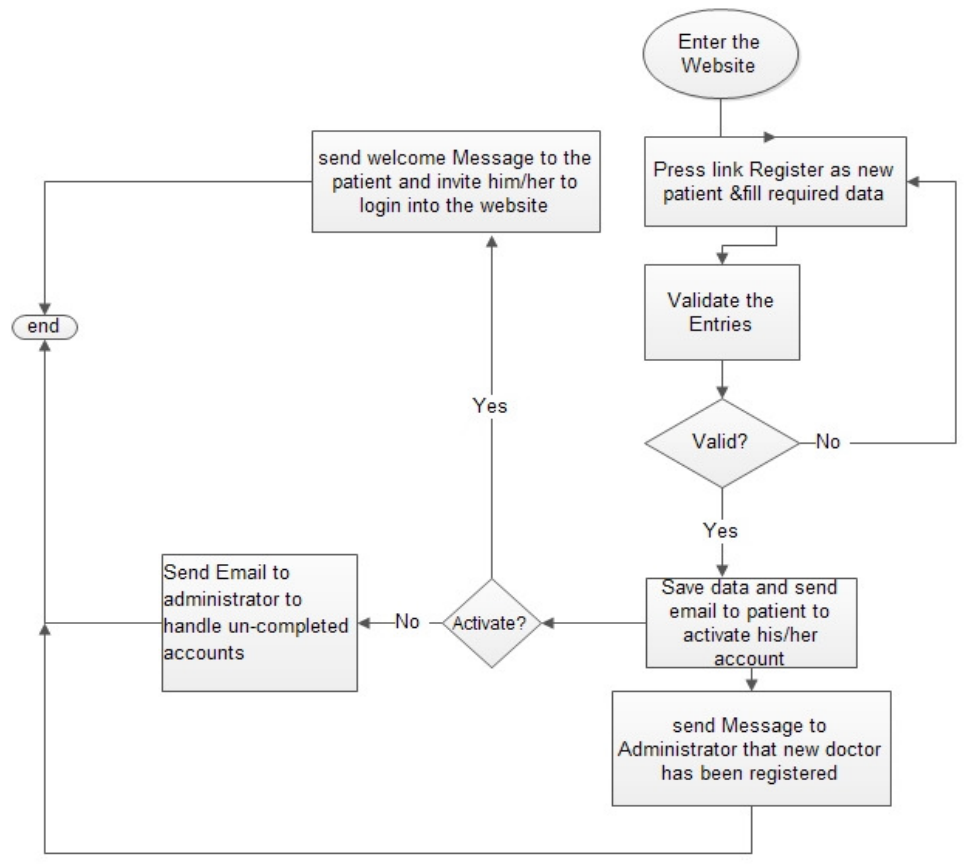

Fig. 6. Patient Registration 


\section{Confirmation of all the Proposed Data, In Particular the Resolved Cases}

Doctor Manage telemedicine services \& their setting (days \& time-slots /cost), If Portal's doctor needs to review/mange telemedicine services, it requires him to login with his account then press "Manage Telemedicine service" link to review his telemedicine services, add new services and change them. If Portal's doctor needs to review/mange telemedicine setting (days \& time-slots /cost), it requires him to login with his account then press "Manage Telemedicine service" link to review service setting, add new times and change days \& time-slots /cost. This is illustrated in Figure 7.
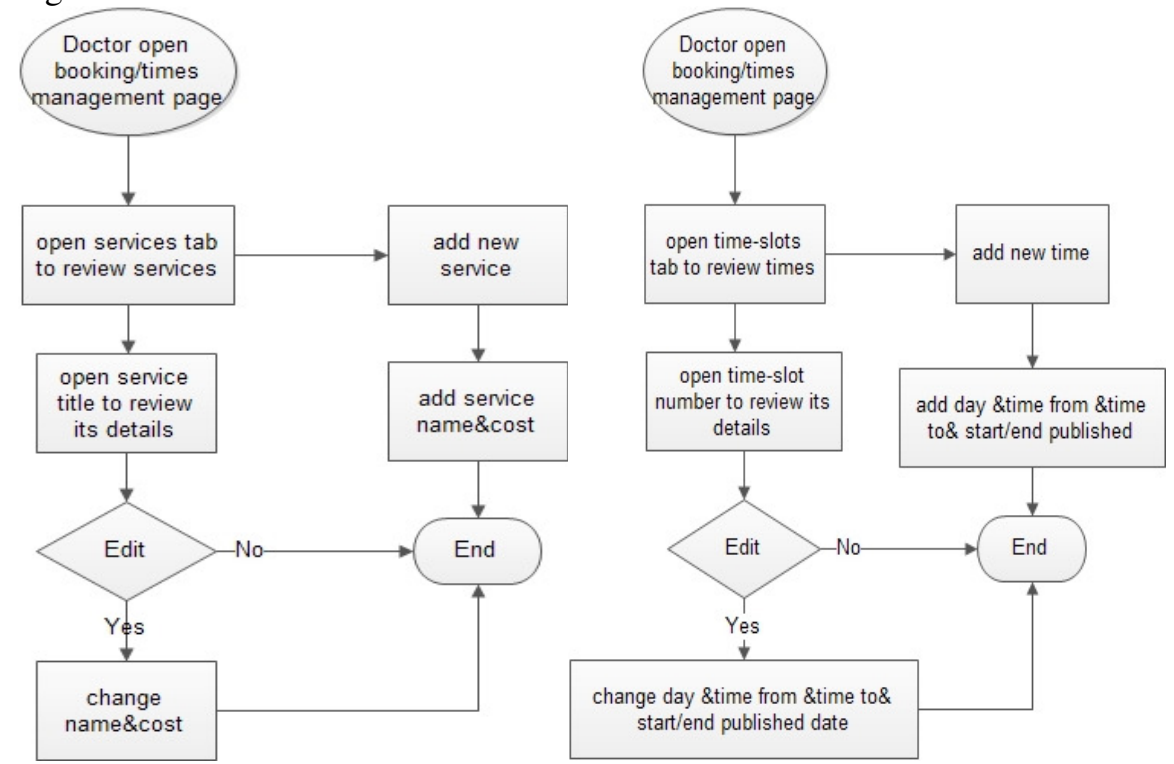

Fig.7. Doctor Manage telemedicine services \& settings

Doctor Manage booking requests, If Portal's doctor needs to review/mange booking requests, it requires him to login with his account then press "Manage Telemedicine service" to review booking requests and user select request to review its details (patient data, time, patient medical history), user can change request status or add prescription and required radiograph \& tests.

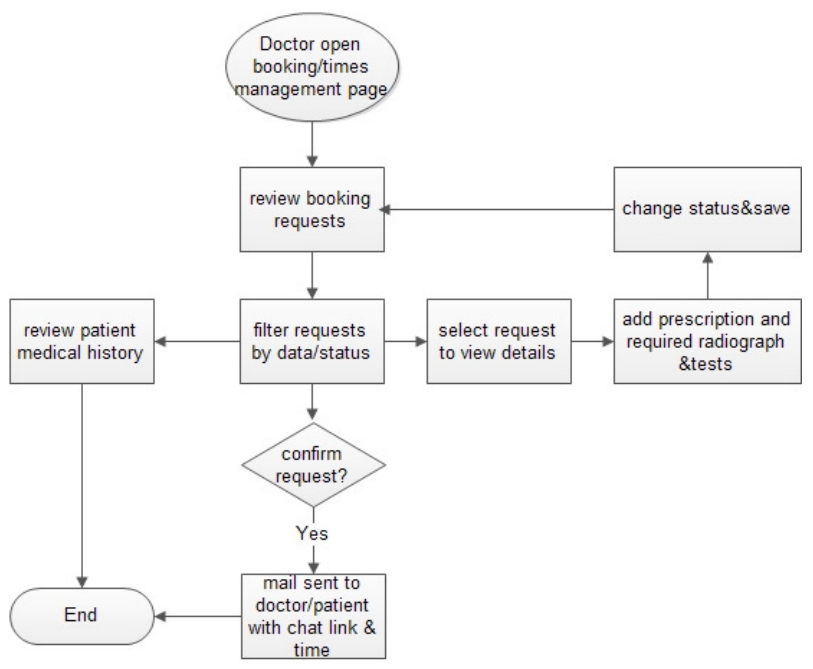

Fig.8. Doctor Manage booking requests 
Patient makes booking $\&$ reviews his booking list, If Portal's patient needs to use telemedicine services and make booking, this requires the patient to review doctor list or search doctors. The patient press "book now" in the icon in front of the doctor he needs. Then the patient fills the form of booking and selects the time and finally presses send. The request will be sent and the payment taken from patient credit. The flow chart of Figure 9 illustrates the booking process.

If Portal's patient needs to review his booking list, the patient enter to Telemedicine link, then user press "booking data" link \& review his booking list. If the conversation with doctor done, patient can review the prescription and required radiograph \& tests. Figure 10 depicts the flow chart of the reviewing list.

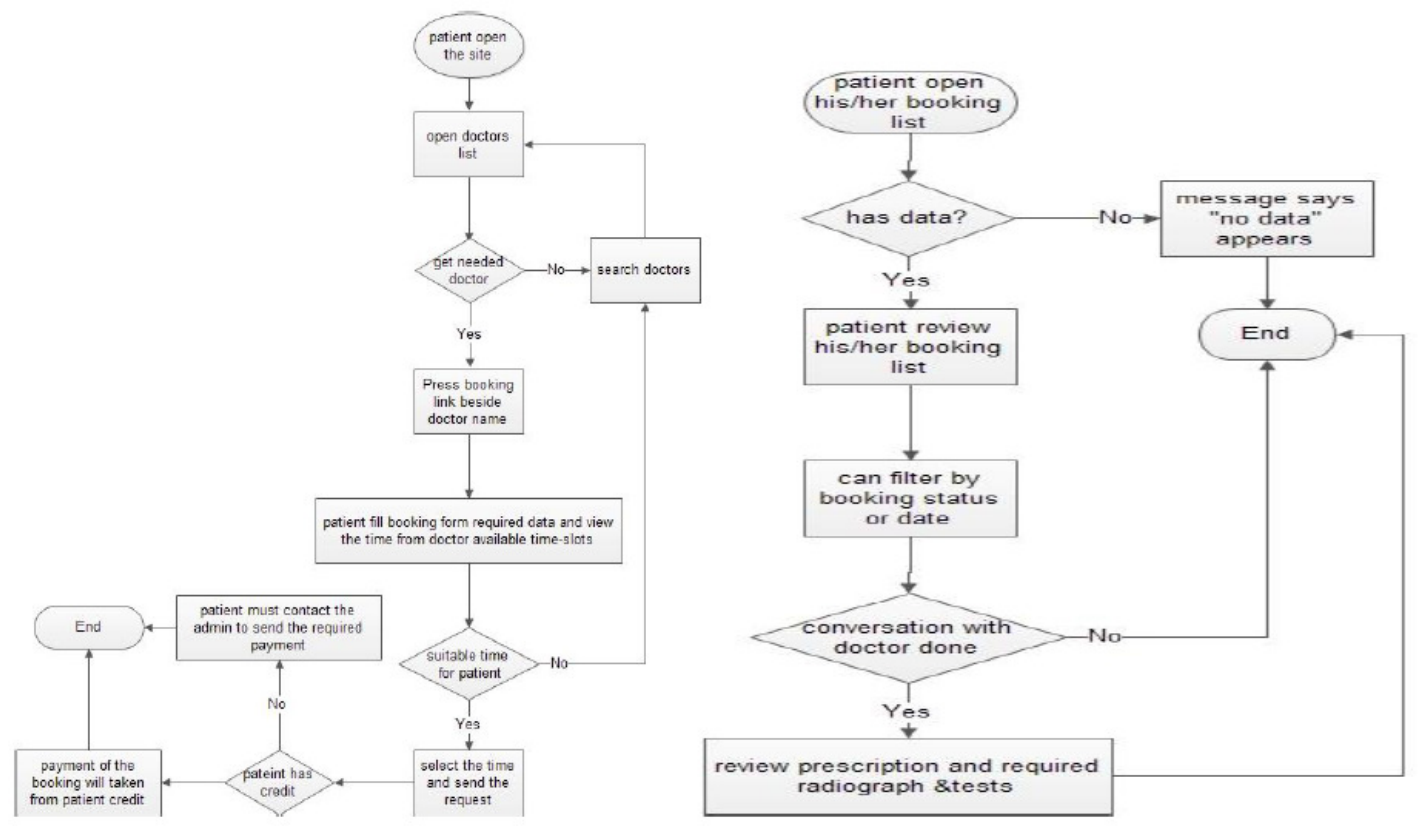

Fig.9. Patient makes booking

Fig.10. Patient reviews his booking list

\section{THE DEVELOPED WORK}

The developed can be followed on the webportal www.ainmedical.com. The telemedicine welcome page is shown in Figure 11 with an overview on the telemedicine application. Figure 12 illustrates the front page of the booking management application. First, the doctor needs to assign his available schedule, fees and confirming the booking as shown in Figure 13. Second, the patient needs to book online and reserve the suitable slot of time if it is available as shown in Figure 14. Once, the pre assigned time slot happens, the link between the patient and the doctor occurs and a video conference is established as shown in Figure 15. After the evaluation of the patient health status, the doctor will choose necessary radiology and analyses that help the doctor to diagnose the case precisely. After the selection of the radiology and analyses, it is send with prescription to the patient side for printing it and follows the doctor instruction. 


\section{About Telemedicine}

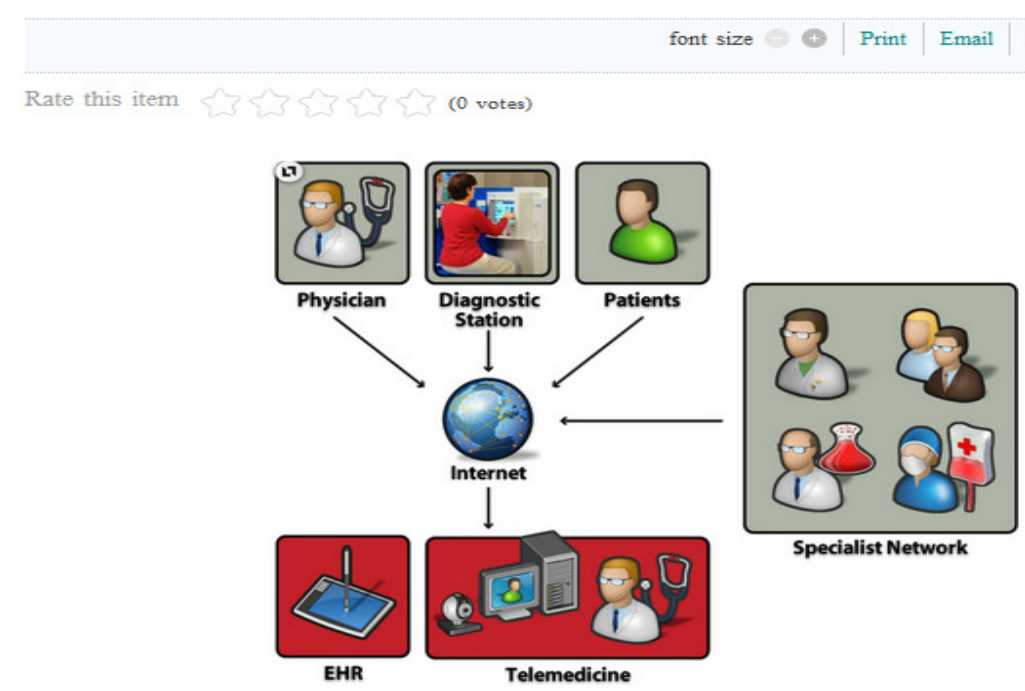

What is Telemedicine?

Telemedicine (Telemedicine) is a medical service very effective remotely using modern techniques, and includes the term telemedicine both the clinical and continuing education remotely, which basically is to give medical care from the medical advice of doctors experienced outstanding mobility live video, or by video footage or still images of the patient or فحوصاته laboratory or diagnostic radiology that are stored and sent to the doctor for diagnosis and follow-up treatment later or directly on the air to the conduct of examinations and the end of conducting surgical operations remotely and from great distances. " and telemedicine next » aims to develop methods and therapeutic and diagnostic services sophisticated and ensure the quality and safety of patient care, in addition to facilitating access to treatment and health care through advanced information technology

\section{The benefits of telemedicine}

\section{Is telemedicine improves the health system?}

There are many benefits and benefits of telemedicine, it is added to improve the health service in general, especially in countries that lack the presence of all disciplines where, it provides medical assistance to patients who need to travel long distances and wait in long lists to get service specialized medical telemedicine after attending experts and specialists to the patient, rather than go the patient and his family to them, which uses information technology and modern communications to collect patient information in digital images «Digital» and stored, and then transported to a remote location at the same time to specialists for their medical opinion or diagnosis of the patient, treatment, or an intervention diagnostic or surgical remotely. and technology is used and a network of telemedicine around the world to provide medical service of counseling simple to medical intervention or surgery for more serious cases such as injuries and accidents, poof emergency and disaster management, and the benefits of telemedicine health system development, minimizing of errors, and build a global community of civilization, but on the level of health, the telemedicine reduces the need for the patient to come to the hospital and thus saves time and money. medical consultations (Teleconsultation) make the patient who has a medical service specific, or patients who have a medical service initial «such as a family doctor, a general practitioner, nurse or home. Access to specialized medical service, which is available in the area in which they reside without having to travel while saving time, effort and money

What hardware and tools we need for telemedicine?

Uses telemedicine hardware and custom software, these devices and programs working to provide solutions and data analysis and storage of medical information, it also allows for the professionals only access and use of these possibilities, and also allow the exchange of information, collaboration and professional dialogue between the institutions and individuals who specialize in the medical field

Fig.11. the front page of the telemedicine application 


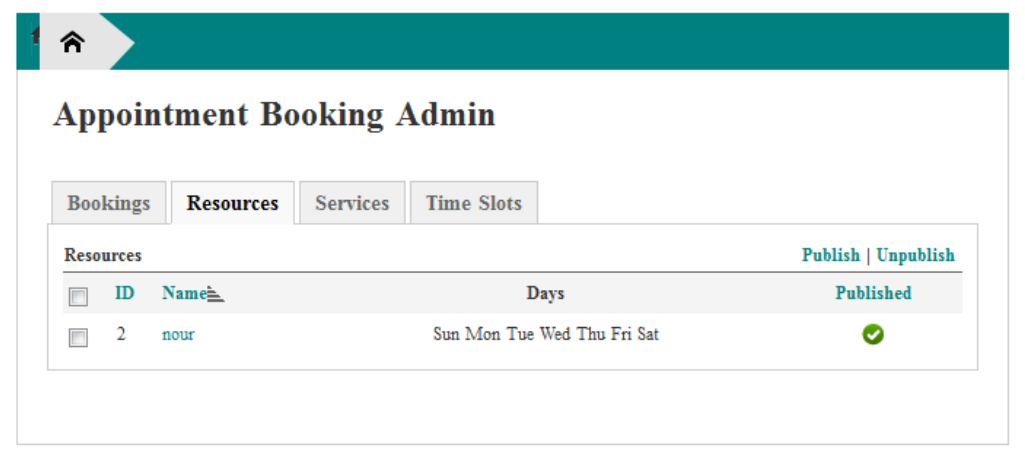

Fig.12. the front page of the booking management

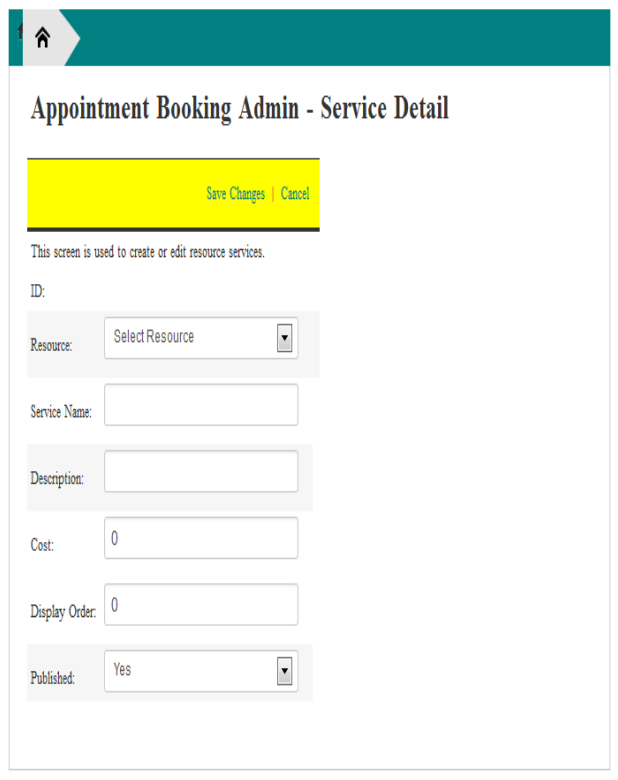

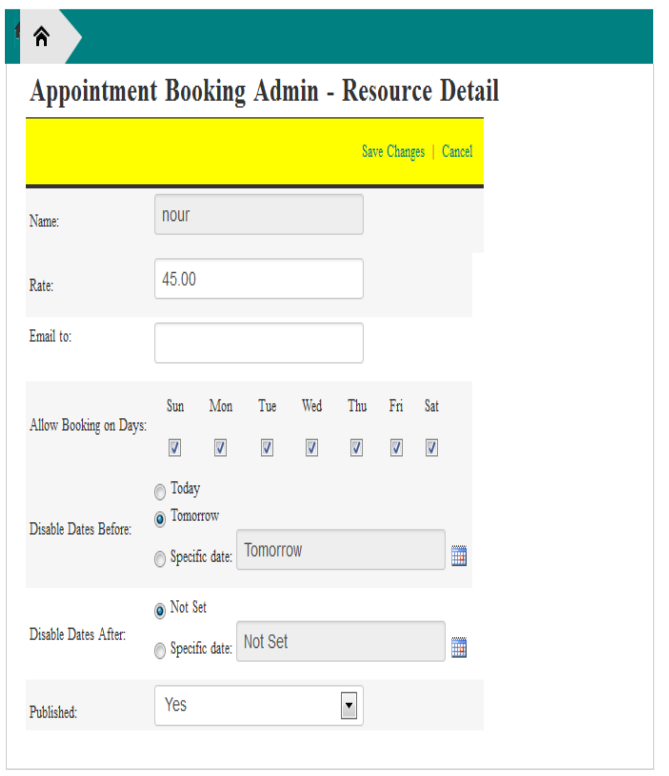

Fig.13. the front page of the doctor booking management 


$$
\text { فحص الدمجلوبين }
$$

تحليل هرمونات البنكرياس

تحليل الهرمونات التناسلية

تحليل هرمونات الغدة النخامية

تحاليل واختبارات هرمونات الغدة الارقية

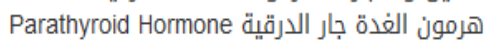

تحليل هرمونات الفدة الكظرية

الأهمية التشخيصية لقياس الهرمونات التناسلية

تحليل السكر وداء السكرى

Liver Function Tests

$$
\text { فحص وظائف الكلى }
$$

تحليل صورة الاهون الكيميائية تحليل بعض الاختبارات الخاصة تحليل الاملاح و تحليل المعادن تحليل الليثيوم Lithium

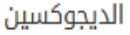

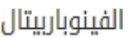
الفينيتوين

حمض الفالبوريك أو حمض الفالبرويك تحليل الهرمونات تأثير مكان تجميع الام على مكوناته حفظ الام أغطية الأنابيب ذات الرموز المولمات المونة مضادات التخثر ( موانع التجلط ) الصورة التي يحلل بها الادم الدمان

جمع عينات اللام ، ادوات سحب الدم الدم

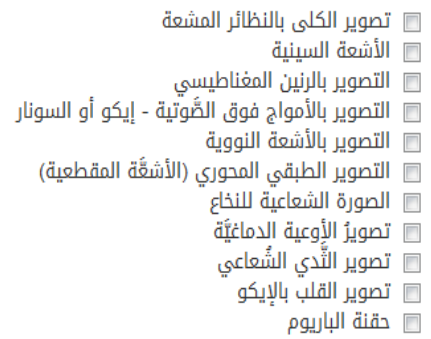

Fig.14. the doctor front page of the radiology and analysis

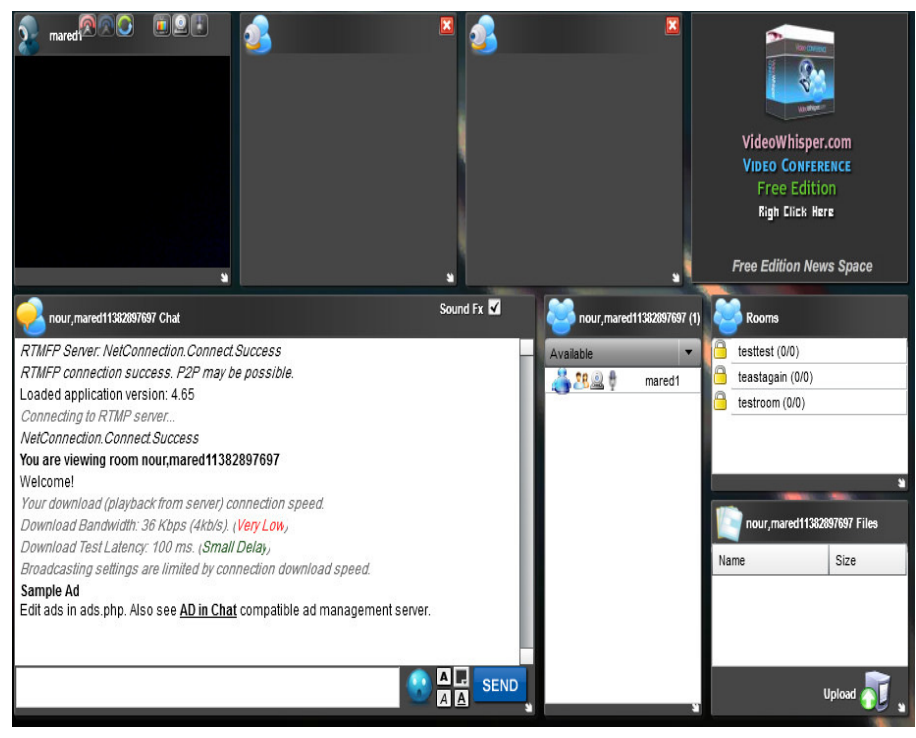

Fig.15. the front page of the patient booking management 


\section{CONCLUSION}

The proposed telemedicine Portal product is an application that allows numerous databases to completely interface through internet. The product developers have concentrated on the medical community as end users specifically, hospitals. The Portal is an innovative new solution in the healthcare industry, bringing common client presentation to users of disparate systems. Multiple hospital information systems can now be accessed, within or outside of the immediate hospital environment, with Java-based "common client presentation." the Portal provides a Graphical User Interface GUI with any of the popular Internet Web browsers, such as Netscape and Microsoft Explorer. The Portal is developed in many different modules and as an Internet application solution; the modules will be run on robust server. One of the most important issue in human health care is the continuous follow up of patients especially those that encounters critical health problems such as heart diseases, blood pressure instability, diabetes, and others or even monitoring the health status of the sports people. For example, high blood pressure is a common risk factor for heart attacks, strokes and aneurysms in Egypt. Thus, the developed portal is considered of main interest to the Egyptian society.

\section{REFERENCES}

[1] A Brief History of NASA's Contributions to Telemedicine, www.nasa.gov/content/a-brief-history-ofnasa-s-contributions-to-telemedicine

[2] History of Telemedicine, The Society for International Space, www.sisc.org/Earth/history.html

[3] Jaakko Lähteenmäki, Joni Ekholm, Emtele, Hannu Kaijanranta, Juha Leppänen, Heart Centre of Pirkanmaa Hospital District, Teppo Veijonen, RESEARCH REPORT, " Information and Communications Technology for Healthcare a Global solution" , No VTT R0017608, 2008.

[4] Lähteenmäki J, "Business model prestudy for telecardiology and global health monitoring services," VTT Report No VTTR1027006, 2006.

[5] A STAR VTT White Paper: "Information and Communications Technology for Health care a Global Solution" 2011.

[6] Saxena SC, Kumar V, Giri VK " Telecardiology for effective healthcare services," J Med Eng Technol. 2003 .

\section{AUTHORS}

Hafez A. Fouad received a BSc. degree in Electronics and communications engineering in 1993, EGYPT and received his M.Sc. and Ph.D. degrees from Ain Shams University in 2001 and 2008, respectively. His M.Sc. is dedicated to Performance Optimization of CMOS RF Power Amplifiers for Mobile Communication systems. The Ph.D. is dedicated to Design and Optimization of Silicon RF Front-ends For Mobile Communication Systems. He now employed as a researcher at the electronics research institute (ERI), Cairo, Egypt. His current research interests are Telemedicine, wireless sensors network, Bioelectronics, Bioinformatics and their applications.

Haythem H. Abdullah received a BSc. degree in Electronics and communication engineering from the University of Benha, Egypt in 1998 and received his M.Sc. and Ph.D. degrees from Cairo University in 2003 and 2010, respectively. His M.Sc. is dedicated in the simulation of the dispersive materials in the Finite Difference Time Domain numerical technique and its application to the SAR calculations within the Human head. The Ph.D. is dedicated on the radar target identification. He now employed as a researcher at the electronics research institute (ERI), Giza, Egypt. His current research interests are design and optimization of microstrip antenna arrays and their applications.
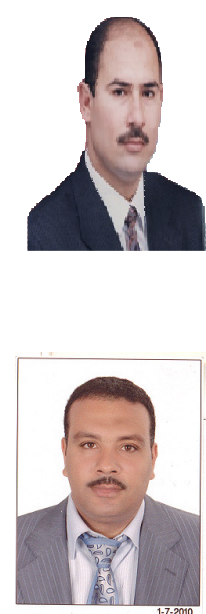